\title{
Selbsthilfe
}

\section{Erhard Taverna}

Dr. med., Mitglied der Redaktion

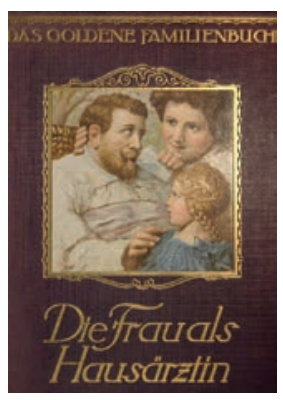

Seit Jahren beklagen sich Spitäler über den zunehmenden Andrang von Bagatellfällen auf ihren Notfallstationen. Kleine Beschwerden, die keine Notfälle sind. Bereits 2002 zeigte eine Untersuchung in den Spitälern Baden und Brugg, dass vier Fünftel der Patienten auch vom Hausarzt hätten betreut werden können. Sie hätten auch problemlos etwas länger zuwarten oder es erst einmal mit Selbsthilfe versuchen können. Dass die Arztpraxis weit billiger arbeitet als das Spital, ist übrigens seit Jahrzehnten bekannt. Viele Kliniken haben ihre Stationen ausgebaut oder eine Notfallpermanence eingerichtet, oft am Bahnhof und rund um die Uhr geöffnet. In vielen Fällen hilft eine Hotline, eine telefonische Triage, diskutiert wird auch eine Gebühr, die in jedem Fall zu entrichten wäre, wenn es nicht zu einer stationären Aufnahme kommt. Die Gründe für diesen Ansturm, besonders an Feiertagen, Wochenenden und Randzeiten, sind vielfältig: zu wenig Grundversorger, viele Ausländer, die nichts anderes kennen, und eine Konsumhaltung, die, sofort und für jede Lappalie, eine maximale Diagnose und Behandlung einfordert. Ein Eintrittspreis wäre durchaus machbar, wird aber aus politischen Gründen abgelehnt. Den Spitälern generiert der Andrang auch Einnahmen, es müssten nur nicht alle zur gleichen Zeit kommen.

Die Situation ist im Grunde paradox. Nie zuvor war es leichter, Informationen zu erhalten, und nie gab es so viele TV-Sendungen über Vorsorge und Krankheitsbilder wie heute. Meist haben sie keinen Lerneffekt, da der Unterhaltungswert oder die Eigenwerbung mehr zählen als eine nüchterne Aufklärung. Die Beiträge sogenannter Fachpersonen verunsichern, man weiss $\mathrm{zu}$ viel und könnte etwas verpassen. Blogs und Foren sind anekdotisch und helfen auch nicht weiter. In manchen Haushalten gibt es keine Apotheke zur Selbstmedikation, kein Hustenmittel, keinen Fiebermesser, keine Binden, Salben oder Wundpflaster. Besonders bei Kindern will man keine Verantwortung übernehmen, man scheut die Auslagen oder hat keine Grossmutter, die Rat weiss.

Einiges war früher vielleicht doch besser. Das goldene Familienbuch Die Frau als Hausärztin erschien 1901 und erreichte 1913 eine Millionen-Auflage. Das ärztliche Nachschlagewerk für die Frau, verfasst von Dr. med. Anna Fischer-Dückelmann (1856-1917), liest sich immer noch erstaunlich modern. Als Mutter von drei Kindern promovierte sie 1896 in Zürich und führte danach eine Praxis für Frauen- und Kinderheilkunde bei Dresden. Das erfolgreiche Pionierwerk wurde zu Recht ein Bestseller, wie später Babyjahre von Remo Largo oder Baby and Child von Benjamin Spock (19031998), eines der meistverkauften Bücher überhaupt. Meine Generation ist vielen Krankheiten und Symptomen, die Fischer-Dückelmann beschreibt, bei Kinderbuchautoren begegnet, die ungefähr zur gleichen Zeit ihre Geschichten schrieben. Josephine Siebe (18701941), Ida Binschedler (1854-1919), Emmy von Rhoden (1829-1885), Olga Meyer (1889-1972) oder Tony Schumacher (1848-1931). Autorinnen und Buchtitel sind vergessen, viele Anneli, Sabinli, Züseli, Christeli, Fritzli und Reserl, Trotzköpfe und Mütterchens Hilfstruppen. Die meisten berichten von Armut, Tuberkulose und Alkohol. Chlorose, Frostbeulen, Fallsucht, Alpdrücken, Badefriesel, Blähhals oder Auszehrung. Auch Zipperlein und Ziegenpeter sind Ausdrücke, die aus der Alltagssprache verschwunden sind. Geblieben sind das Heimweh und die Bruchbinde, die niemand mehr braucht. Frau Doktor hat in ihrem Nachschlagewerk Rat und Tat für alle diese Symptome bereit. Auf tausend Seiten werden Anatomie, Gesundheitspflege, Kinder- und Frauenkrankheiten und vieles mehr abgehandelt. Die wichtigsten Krankheitsbilder sind mit zugehörigen Untersuchungstechniken beschrieben. Sie werden mit Bädern, Kompressen, Wickeln, Aufgüssen und Inhalationen behandelt. Eine Verbandlehre gehört dazu, die Krankenlagerung ebenso wie die Korrektur von Haltungsschäden. Das Buch wurde mehrmals überarbeitet und ist in vielem veraltet. Doch die Sprache ist immer noch erstaunlich präzise, nüchtern und Reformlehren verpflichtet, die immer noch aktuell sind. Heutige Jugendbücher haben andere Themen. Krabat, Momo, Harry Potter oder Tschik müssen sich mit neuen Problemen herumschlagen. Die grossen Epidemien sind vorbei, Gewalt und Armut in die Randzonen verbannt. Vielleicht spiegelt sich in diesem Fortschritt auch ein Stück Gesundheitswohlstand, der die Selbsthilfe verkümmern liess.

\section{Literatur}

Fischer-Dückelmann A. Die Frau als Hausärztin. Ein ärztliches Nachschlagebuch für die Frau. München: 1921. 